\title{
a figura da mulher no imaginário masculino no mundo dos coronéis
}

\section{Tieko Yamaguchi Miyazaki}

Professora na UNESP - São José do Rio Preto

ABSTRACT: Women usually play actantial and thematic roles, secondary ones in rural aristocratic patriarchal universe. However, under this apparent preterition, even in a discourse written by a man, it is possible to verify how the feminine figure, in masculine imagination, plays central roles by conducting the other's and everybody's destinies.

KEY WORDS: Roles - Figure - Imagination - Feminine - Discourse.

Dizer que o mundo dos coronéis - da aristocracia rural - é um mundo masculino é incorrer numa tautologia. Não desmentida sequer por personagens femininas - históricas ou ficcionais - que ousaram comutar com os homens papéis - actanciais e temáticos - a estes especificamente reservados. Mais que essas figuras de primeiro plano, interessam por ora aquelas que se encarregam de papéis a elas atribuídos dentro da estrutura de um universo masculino.

A qualificação de masculino não se deve entender como decorrência natural do fato de se tratar de narrativas escritas por homens. Melhor, até por isso, na medida em que o traço masculinidade (vs. feminilidade) apareça impregnando a instância da enunciação que se projeta no enunci- 


\section{Tieko Yamaguchi Miyazaki}

ado de maneiras várias - atores delegados do sujeito enunciativo, observador social, aspectualização, modalização etc. Importa-nos ver como, assumindo papéis femininos - seja do ponto de vista biológico, seja do ponto de vista social -, essas figuras são trabalhadas pelo e no discurso masculino.

Reportando-nos ao ensinamento de C. Lévi-Strauss, no código de parentesco as mulheres são o elemento que circula dentro de uma sociedade. Seja nas relações prescritas como o casamento legal ou legalizado ou proibidas (adultério feminino), seja nas das injunções negativas (não prescritas e/ou não-proibidas) como o adultério masculino, a prostituição, consentida ou não.

A perspectiva masculina reserva à mulher, no simulacro com que lidam os homens, uma localização secundária numa escala formal hierárquica, e um valor também secundário numa escala semântica, que se entendem - posição e valor - corroborados pela distribuição de homens, de um lado, e mulheres, de outro, na estrutura de parentesco ou de relações sexuais não-legais.

Como no jogo infantil do anel que corre de integrante a integrante pela mão do que ocupa o centro da roda, à mulher, objeto que circula, cabe o lugar do anel e, ao homem, àquele que o recebe, o lugar de participante, imóvel, do jogo. No entanto, o lugar fixo e igualitário de cada integrante do jogo é duplamente determinado pelo anel. O participante a quem é dado o anel se define, nessa estrutura, como aquele que tem o anel e que, assim marcado positivamente, se diferencia de seus parceiros que não o têm. De qualquer forma, o que nos interessa é que a mulher-anel determina a posição masculina. Inverte-sc, pois, a leitura axiológica entre o fixo e o móvel, o objeto que circula e o sujeito que o recebe. É isso que pretendemos examinar em Bangüê romance de José Lins do Rego, publicado em 1934.

A análise de tal tema exige que se tome como pressuposto o seguinte: à maneira dos contos populares, como indica W. Propp, ocorre em Bangüê uma triplicação de função. No caso, a fase de 


\section{a figura da mulher no imaginário masculino no mundo dos coronéis}

competencialização do sujeito para o reerguimento do engenho Santa Rosa.

1) Todo o primeiro parágrafo que abre o romance sintetiza o resultado da primeira tentativa de efetivação do contrato: a do comprometimento de adquirir os conhecimentos necessários à figura do novo senhor de engenho (misto de bacharel e coronel). Todo o parágrafo é a manifestação da sanção negativa do percurso realizado no Recife e, conseqüentemente, negação das virtualidades inplicadas, indispensáveis ao fazer transformador;

2) Apesar disso, toda a primeira parte do romance, intitulada " $O$ vello José Paulino", corresponde a uma segunda tentativa em que se defrontam os destinadores, o velho coronel e o próprio engenho, e os antidestinadores, os tios Juca e Sinhazinha. A opção de Carlos pelo posto de promotor encerra o confronto, o contrato não se efetua com a desqualificação do sujeito-destinatário, e o objeto mágico não é transmitido. Resulta, assim, uma situação de fato, com a qual se responde à indagação inicial do romance', e que assinala o ponto final de todo um programa narrativo, sem carregar no bojo qualquer virtualidade que indique direção ao desenvolvimento posterior do relato; ${ }^{2}$

3) No entanto, aparece um ator, alienigena, que se encarrega de uma terceira tentativa.

Conseqüentemente, é de forma abrupta que se dá a aparição de um novo ator, cuja chegada ao engenho, inesperada, é dada pelo narrador como fato consumado: "Chegara ao engenho para passar uns tempos. O meu avô recebera o pedido de cavalo para a estação, aborrecido" (p.48). ${ }^{3}$

1. "Vamos ver para que dá o senhor" é a frase com que o avô, coronel José Paulino, recebe o neto de volta do Recife.

2. Sobre a triplicação da prova qualificante, Cf. MIYAZAK1, 1.Y. Bangüê. romance memorialista?. São José do Rio Preto, Stylos, 1992.

3. Todas as citações se fazem pela 2 a edição, Rio de Janeiro, José Olympio, 1969. 


\section{Tieko Yamaguchi Miyazaki}

Curiosamente, a razão do deslocamento desse ator desconhecido, da cidade para o engenho, é uma carência: segundo diagnóstico médico, "doença dos nervos" que requer ares do campo. Já de entrada, ao espaço rural é indicado o papel de doador de um bem que se figurativiza como "ares", e cujo efeito não é propriamente da ordem somática.

Em contraste, portanto,com a perspectiva de Carlos que culmina, no processo de embrutecimento, com a cena das moscas, Maria Alice se apresenta de início como beneficiária do engenho. Ademais dessa posição passiva, ela não traz marcas que lhe confiram destaque. Melhor ainda, é justamente essa ausência de traços relevantes que se fará a sua característica maior, identificável com naturalidade, a qual lhe permite, sem esforço e planejamento,assimilar-se ao mundo do engenho. Como que retribuindo, numa relação de troca, a doação a ela feita pelo novo mundo, ela injeta neste uma nova energia.

Num levantamento rápido na apreciação do narrador quanto à atuação desse ator alienigena, ver-se-á que ele aparece como reagente que suavemente confere legitimidade ao que na comunidade há de legitimo, fazendo, concomitantemente, denunciar-se o que há de espúrio.

Nesse fazer transformador de Maria Alice, a primeira modificação mais decisiva apontada pelo narrador é o da casa-grande, tanto na espacialidade do edificio, revivificado pela abertura de janelas e portas e transformado em espaço cheio com a presença de luz e vento, como pelo preenchimento do vazio humano. Com relação a este, ela promove uma intensa atividade da ordem do fazer-fazer. $O$ primeiro a revitalizar-se é $o$ avô que ela leva a todo um movimento de expansão, em contraste ao de retraimento antes já visto, não só no interior como no exterior da casagrande. Como se sabe, o grito faz parte de José Paulino, senhor de engenho, como forma não só de mando, mas de onipresença pela extensão da propriedade. É exatamente dele que se vale o doador, para levar o outro ao fazer ("Gritava para ele, abrindo as janelas, à noite, para entrar ar."), numa imagem en espelho confirmada pela resposta do coronel ("O velho José Paulino até já gritava para os moleques", p.50). 


\section{a figura da mulher no imaginário masculino no mundo dos coronéis}

O indício maior do renascimento de José Paulino encontra-se, no entanto, no ressurgimento de seu amor pelos frutos colhidos no pomar. A referência ao passado em que tinha o mesmo gesto de presentear a filha Maria com laranjas, abre a dimensão simbólica do gesto agora repetido com Maria Alice.

Também Carlos é acordado de sua apatia, para uma atividade que no texto aparece expressa duas vezes pelo mesmo lexema: reparar. A fixação cognitiva do espírito no reconhecimento de algo que não só ele. Curiosamente o efeito da ação de Maria Alice sobre o moço repercute de duas formas: a necessidade de sair do quarto e de ler, ou seja, são formas de suprir dois tipos de carência inter-relacionados: o do conhecimento do próximo e de si mesmo. O tema da literatura - e da leitura - é reintroduzido, assim, como necessidade, não como algo imposto mas requerido.

Concomitante a esse trabalho de conjunção reflexiva, uma outra é promovida por Maria Alice, a mesma tentada na prova de qualificação anterior: a conjunção de Carlos com o engenho, a qual exige, como antes, a mediação da aceitação por parte do neto do coronel em sua realidade presente. Trata-se, na verdade, de uma mediação dupla: o interesse amoroso de Carlos por Maria Alice precisa mediar, legitimando ao mesmo tempo a sua função, a aproximação avô-neto para chegar-se à conjunção Carlos-engenho. Nessa performance, a visitante, numa primeira etapa, desenvolve um programa narrativo tendo como temas seja o afeto de paifillha, em que Maria Alice comuta papéis com a filha Maria, seja a piedade com que a moça cuida da enfermidade do coronel ou ainda a fraternidade com que ela se refere ao passado do senhor de engenho. E numa segunda etapa dessa conjunção ela promove o contato direto do sujeito com o engenho: primeiro, com a fisicidade deste $\mathrm{e}$, segundo, com o engenho enquanto comunidade produtiva.

Com a chegada de Maria Alice, Carlos não só se desloca de seu quarto para as demais dependências da casa-grande como se movimenta por todo o engenho. Ao contrário do que se passa na primeira parte do romance, os seus passeios (o que significa passeio?) ocorrem pela ma- 


\section{Tieko Yamaguchi Miyazaki}

nhã. O primeiro deles se faz "pela estrada", como um deslocamento sem um ponto de chegada fixado a priori. É nesse momento de aparente ócio que Maria Alice se revela como doadora.

Já na descrição do caminho percorrido ("O caminho feito para um casal de namorados, de tanto cheirar o muçambê e tanto enfeite de trepadeiras pelas estacas do cercado", p.58), se observa o efeito do fazer transformador da moça, modalizando o destinatário-sujeito como reintegrado em seus sentidos que o colocam na posição de sujeito de querer (amar). Mas esse papel actancial da mulher fica mais clara pela referência do narrador à sua atitude, isto é, a sua disposição para: "Gostava de chamar a atenção para as coisas bonitas que via" (p. 63). Ou seja, não há somente ver, mas compartilhar a experiência; ela é o dedo apontando as coisas, num saber-ver que se comunica ao outro: "minha companheira mostrava-me um pé de cardeiros todo sangrando nos seus frutos encarnados" (p.68).

Mas a pedagogia subentendida pressupõe um querer-saber que exige do sujeito uma atitude sempre inquiridora: "Maria Alice quis saber (...).", "Perguntava-me", "Prestava atenção a tudo". Ela conduz Carlos a um desmascaramento em que ele se declara modalizado por um não-saber (sobre o engenho), cuja causa, também ela lhe revela, está na atitude do sujeito que não quer saber e que, portanto, não se aplica à sua aquisição. Todo esse processo de doação complexo,portanto, enquanto parte da transformação do sujeito de modalização endotáxicas para exotáticas, pode ser detectado no emprego estilístico não só de verbos como de pessoas verbais.

Com èfeito, observa-se que, num primeiro momento, a função de sujeito sintático é expresso normalmente por lexemas ou pronomes que se referem a Maria Alice, enquanto Carlos ocupa a posição de objeto indireto, de destinatário, portanto, da ação do sujeito. Mesmo quando o -predicado vebal aparece como perguntar, trata-se na verdade de uma pergunta que revela, pelo processo de estranhamento a que obriga o interlocutório. Nessa fase, os lexemas indicadores da atividade de Carlos são da esfera do ouvir e tendo como objeto a fala do outro e, como conse- 


\section{a figura da mulher no imaginário masculino no mundo dos coronéis}

qüência, da esfera do aquiescer. Todo esse processo de doação/recepção, em que predomina a primeira função, encontra-se sintetizado na primeira página do capítulo III: "Nós dois andávamos pelo Santa Rosa vendo tudo com os seus olhos" (p. 61).

As considerações acima tornam mais clara uma significação do capítulo seguinte, dedicado ao passeio à Mata do Rolo. Toda uma mudança estilística se observa, quando o mundo natural é descrito sem a mediação anterior de Maria Alice. A comunicação verbal se faz pela perspectiva do homem, em que o mundo exterior comparece apresentando-se ao sujeito agora capaz de vê-lo. Abundam os componentes sensoriais que se convertem em sensuais, devido ao cruzamento da intriga amorosa. Essa conotação permanece durante toda a segunda parte do romance, criando um ambiente de fecundidade. É dentro dessa perspectiva que se insere um novo tema: o da integração direta da sujeição com a terra num processo de naturalização do homem que só assim se humaniza:

"Descemos dos cavalos para ver de mais perto as" coisas que nos rodeavam. Era preciso tocar na terra com nossos próprios pés. ficarmos mais humanos, ali onde tudo nos convidava para a vida" (p. 63).

É nessa fase de conjunção direta do sujeito com a terra e de primeiro contato amoroso deste com Maria Alice que os sujeitos individuais aparecem amalgamados, estilisticamente inclusive, como sujeito coletivo: "Paramos para ver outra orquidea em botão" (p. 63), diz o narrador, e mais adiante: "Paramos os dois, instintivamente, para olhar o trabalho penoso..." (p.65). A homologação da qualificação obtida se dá, depois, junto à mesa de jantar pelo destinador - o avô - que outorga o objeto mágico - a alegria. Por isso tem a função de confirmar como verdadeiro o contrato realizado o segmento subseqüente em que ocorre novo passeio: Carlos, desta vez, o realiza só e a sua narração mostra a inversão havida na distribuição de funções e papéis actanciais. Carlos é, agora, o destinador, Maria Alice - ausente --- o destinatário, e o objeto é todo o engenho. A partir de tal conjunção de Carlos com o engenho em sua fisicidade, parte ele a integrar-se nessa unidade produtiva, sempre 


\section{Tieko Yamaguchi Miyazaki}

através do crivo crítico de Maria Alice.

Sintetizando: após a primeira tentativa frustrada de qualificação de Carlos como futuro senhor de engenho, em que o destinador do contrato é encarnado pelo próprio avô, seguindo um princípio de triplicação, como se verá mais adiante, entra em cena um novo ator, alienígena que vai provocar em Carlos todo um renascimento de suas potencialidades masculinas e, concomitantemente, revelar-lhe o mundo verdadeiro do engenho: tanto o engenho, enquanto propriedade de terra, quanto enquanto comunidade produtiva; vai revelar-lhe também a si mesmo e o outro através da literatura. Assim, aquela que viera como beneficiária dos bons ares do campo, transforma-se em destinadora de un saber-ver (a si, aos outros, ao engenho).

Para compreender mellor a segunda prova de qualificação há pouco analisada, é preciso examinar as funções e papéis desempenhados por Maria Alice, em comparação aos demais atores femininos que compartilham com Carlos vários programas narrativos de temática amorosa.

Já na primeira parte do romance, em programas narrativos de uso, aparecem duas figuras femininas - Maria Chica e Laura - como parceiras de uma relação heterossexual com Carlos. Estão tais figuras marcadas por determinações que as localizam em pólos opostos em duas ancoragens narrativas básicas: a temporal e a espacial. Laura opõe-se a Maria Chica não só porque pertence ao passado de Carlos - e ela comparece à cena através de cartas (dela e de Mário) para dizer exatamente isso, ou seja, que um segmento da vida de Carlos é um segmento esgotado - mas também porque pertence ao espaço ausente urbano. Maria Chica é, assim, em contrapartida, o rural, autóctone, plenamente presente no aquiagora do sujeito.

Apesar dos traços disjuntivos apontados, elas equivalem-se pois, na relação com Carlos, ambas comparecem encarnando sujeitos a que se nega esse mesmo papel, de sujeito. Na convivência amorosa, em que os sujeitos se buscam mutuamente como um mesmo objeto-valor (prazer, amizade,afeto), as duas mulheres são reduzidas de sujeito do querer, em 


\section{a figura da mulher no imaginário masculino no mundo dos coronéis}

permuta posicional com o homem, a objeto-valor, fato só possivel na medida em que o relacionamento anoroso é sobredeterminado por uma relação de compra e venda. A relação mercantil básica, tacitamente reconhecida como vigente, em que à mulher - e não ao homem - cabe a função de objeto-valor, aparece, no caso da mulher de empregado, como direito adquirido pelo uso desde a escravidão, decorrente, portanto, do poder econômico do senhor de engenho, e como adquirido por quem tem poder e dinheiro, no caso da prostituta.

Num caso e no outro, os programas narrativos parecem tematizar o abuso de poder, comum numa coletividade como a dos engenhos e de cidades como Recife. No entanto, a contrapelo, tematiza-se una outra questão, a não-legalidade e/ou não-legitimidade de tais relações, enquanto fundadas sobre o arbítrio do poder. No caso da prostituta, que procura apagar a natureza mercantil recoberta pela.figura do sexo, questiona-se a legitimidade de tal relação de compra e venda; já no que toca à Maria Chica, na condição de mulher de outro, questionam-se a legalidade da posse do dominado pelo dominador e a legitimidade desta mesmo quando assegurado pelo querer do dominado. Essa dupla questão - da legalidade e da legitimidade - volta a tematizar-se na figura de Maria Alice, pois, como Maria Chica, é mulher de outro, mas não exiśtindo a relação mercantil, como no caso de Laura, ao contrário desta é também sujeito de um querer cujo objeto-valor é Carlos.

Tomando-se como referência esse quadro paradigmático que conjunge e disjunge as três figuras femininas, é necessário que se observe em que ponto da narrativa fazem elas entrada.

A primeira referência, demorada, a Laura ocorre com a carta de Mário. A distância temporal e espacial produzindo uma debreagem entre Carlos enquanto sujeito cognitivo e Carlos sujeito do fazer (no passado e no Recife), o leva à elaboração de uma auto-imagem em que ressalta uma dupla carência: a desqualificação de Carlos como sujeito de amar (fisicamente - "antigamente saia da cama de Laura com nojo dela", p. 58), e como sujeito de bem-querer ("Quisera mesmo ter gostado de Laura, mais do que gostava”. p.58). A segunda aparição da prostituta se dá em 


\section{Tieko Yamaguchi Miyazaki}

forma de sua carta. A resposta de Carlos faz ver nela o ator em que se representa o outro termo da opção inicial de Carlos (Santa Rosa ou Recife), pois graças à carta de Laura Carlos torna-se objeto de manipulação do Recife que trabalha pela sedução:

"Tive então saudades de Laura e de toda a minha vida de Recife, dos anos de colegas. mulheres e jornais. Por que não dava o fora do Santa Rosa e não pegava outra vez o fio daquela existência fácil, divertida" (p.40).

Trata-se de uma sedução especiosa, uma vez que o simulacro ai criado para a representação do Recife não coincide com o de outras passagens. De qualquer forma, o papel actancial de sujeito de uma performance de sedução, desempenhada por Recife na disputa do objeto Carlos ao engenho, só ganha sentido pela aproximação dos papéis temáticos e actanciais encarnados por Maria Alice, como se verá mais adiante.

Por ora é preciso pontuar que a relação amorosa com Maria Chica e a lembrança de Laura promovem em Carlos o aparecimento de um percurso narrativo cujo objeto é o amor. A partir da carência inicial, recolocada em pauta pelas cartas de Recife, Carlos faz-se sujeito de um percurso em que o objeto-valor se gradua, englobando-se sucessivamente, do amor carnal ao amor fraterno, intermediado pela harmonia de ambos. É o confronto com o ponto de referência da literatura, promovida a virtualidade desejada, que ele identifica a função do amor nas histórias em análise:

"O amor que eu conhecia nunca me dera força para coisa alguma, nunca me elevou nem me rebaixou, aluindo-me de minhas bases. Que secura era aquela minha? No intimo me via pequeno demais, menor que todo mundo" (p.43).

Isto é, o resultado é a desqualificação de Carlos como sujeito de querer (bem), em sua relação consigo e com o mundo. Desqualificado o sujeito, toda questão inicial se coloca, como a da prioridade, pressuposta 


\section{a figura da mulher no imaginário masculino no mundo dos coronéis}

a qualquer programa, de sanar tal secura. Carência, portanto, não de um objeto hipotético (a mulher) mas de um objeto hiponimio (do querer bem). É com esse sentido que, assim introduzida, Laura permanece como o contraponto necessário ao estabelecimento do sentido tanto da figura de Maria Chica quanto da de Maria Alice. Basta lembrar que, enbora seja Maria Alice a figura central, na segunda parte do romance Laura volta à cena, ainda que no nivel de narração, quase no final, no capitulo VIII, em que o sentimento de Carlos por Maria Alice é expresso através da evocação da Laura. Eć praticamente a carta de Laura que introduz na história de Carlos a figura de Maria Chica: graças ao trampolim de seus amores juvenis, já esquecidos, Maria Chica aparece para figurativizar o objeto do desejo carnal assim desperto: "Pela primeira vez, confessa o narrador; no Santa Rosa me chegou uma vontade danada de andar com mulher" (p. 44). Embora valorizada por seus predicados de fêmea, nesse primeiro momento, Maria Chica permanece como objeto virtual do querer de Carlos e que só se realiza na segunda parte do romance. Mesmo então, ela se apresenta como objeto realizado de um desejo cujo objeto visado, deceptivo, permanece virtual: o desejo de Maria Alice desperto em sonho se realiza em Maria Chica.

Nesse jogo de papéis - de destinadora de desejo e de objeto real dele -, desempenhados pelas figuras femininas, desenvolvem-se dois percursos narrativos paralelos que tematizam a relação amorosa. Correm paralelas a história do envolvimento de Carlos e Maria Chica e a de Carlos e Maria Alice.

A cavaleiro, desempenhando o papel critico de leitor delas, coloca-se Carlos cujo fazer cognitivo, tanto no nivel de enunciação quanto de enunciado, é regido por códigos identificáveis com os de uma civilização urbana. Entretanto, prenunciando papéis que Maria Alice virá a desempenhar, Carlos realiza uma sintomática delegação de papéis. Calando-se sobre si mesmo com respeito à cabocla, ele enviesa o seu fazer predicativo, atribuindo à visitante juizos calcados em códigos urbanos, segundo os quais a satisfação dos instintos, pressupostos no ato amoroso, estaria proscrita, quando tem por parceira pessoa de classe inferior. Ou seja, aos olhos de Carlos, Maria Alice encarna o destinador tanto doador - 


\section{Tieko Yamaguchi Miyazaki}

dos códigos - quanto sancionador, na medida em que atua nele a oposição bacharel/neto de senhor de engenho. "Se me visse assim, com aquela cabocla de engenho me emporcalhando" (p.54), preocupa-se Carlos, confundindo os termos prescrito-proibido e seus contrários. A legalidade questionada com relação à mulher de empregado é vencida pela legitimidade conferido pelo querer dos sujeitos desde que socialmente equiparados, quando também se legitima o objeto do querer carnal, ainda que proibido.

Além da disparidade quanto à sanção - positiva ou negativa dependendo das condições sociais das parceiras e resultante da perspectiva urbana de julgamento, o juizo atribuido pelo sujeito ao destinadorjulgador traz à baila a disforia dos costumes considerados como próprios do coronel em oposição à urbanidade atribuída ao bacharel. A equiparação, feita por Carlos, de sua atitude à de seus antepassados, através da qual Maria Chica, não-escrava legalmente, passa a equivaler a escrava de fato, e a preocupação em negá-la aos olhos de Maria Alice,enquanto destinador-sancionador - "que não abrisse o bico senão mandava quebrá-la de pau" (p.75), manifestam a duplicidade do sujeito nesse momento da narrativa.

Com a notícia da gravidez - já em curso a relação amorosa entre Carlos e Maria Alice - e a ameaça do senhor de engenho, Maria Chica desaparece para só voltar na terceira parte, agora, desempenhando novo papél temático: o de mãe do filho de Carlos, impondo, ao mesmo tempo, um novo papel também ao bacharel: o de pai.

Por ora basta compreender a articulação dos atores femininos que se relacionam amorosamente com Carlos, nesta primeira parte do livro. Verifica-se que, a partir do núcleo comum, de objeto comercializável, Maria Chica e Laura passam a distanciar-se graças a traços que as distinguem socialmente. Desses, para o propósito destas considerações, destaca-se como fundamental o fato de que a prostituta de bordel se situe na área urbana e que a mulher do empregado do engenho se identifique como da área da aristocracia rural. No primeiro caso, ocorre uma relação entre prostituta e estudante; no segundo, entre a empregada e o senhor de enge- 


\section{a figura da mulher no imaginário masculino no mundo dos coronéis}

nho. No primeiro caso, a relação é carnal e totalmente disfórica pela esterilidade dupla, de prazer e de prole. Já no segundo, a falta de qualquer referência ao aspecto erótico acima apontado leva a supor pelo menos uma não disforia equivalente à do primeiro; quanto à procriação, 0 resultado é o de uma relação fecunda.

Com base em tal quadro, correlacionar Laura com o efeito da permanência de Carlos em Recife produz uma leitura sintetizável da seguinte forma: a inutilidade de sua estada na capital, mensurável pela esterilidade de seu resultado em todas as faces da experiência humana. Tal leitura, por contraste, leva a concluir pela não-esterilidade do relacionamento de Carlos com o engenho em, pelo menos, nos dois aspectos acima apontados. $\mathrm{O}$ caso Maria Chica não pode, ao que parece, ser reduzido, como o caso Josefa, a exemplificação figurativa do comportamento padrão do senhor de engenho, tematizando a vigência de fato da ideologia escravocrata.

Tal quadro, constituído de termos contrários e contraditórios a se combinarem, compõe uma situação narrativa que prepara a entrada em cena do ator feminino principal. $\mathrm{O}$ enunciado de estado que sintetiza tal situação coloca Carlos como um sujeito - senhor de engenho - em conjunção com o objeto-valor maior que o define: o poder, no centro do qual se instala um jogo de forças entre duas linhas ideológicas em que uma - a rural - é dada pressupostamente como disfórica, e outra - a urbana - como pressupostamente eufórica. $\mathbf{O}$ caráter deceptivo de tal distinção polarizante, delineada isotopicamente por dois percursos narrativos protagonizados por Laura e Maria Chica, supõe resolver-se com a chegada de Maria Alice.

"Moça fina da cidade", casada com parente próximo, empregado na cidade, sem filhos, de uma beleza "que não precisava de tática para vencer os outros", assim é descrita a visitante. Nessa descrição, identificam-se percursos temáticos e figurativos que tornam o ator o fulcro de percursos narrativos virtuais que se estruturariam em esquemas harmoniosos. Ao modo do parecer, um dos percursos figurativos compõe o tema da mulher estabilizada num tipo de sociedade, graças a predicações 


\section{Tieko Yamaguchi Miyazaki}

eufóricas conferidas pela natureza ou pela sociedade. No entanto, a própria razão de seu deslocamento espacial - problemas de saúde - desvela o modo deceptivo de tal configuração, catalisadora de uma complexidade que justifica mais tarde os papéis a ela atribuidos.

Tal complexidade começa a delimitar-se quando se confronta a descrição acima e o quadro há pouco delineado das duas figuras femininas anteriores. Ao contrário destas, Maria Alice é objeto duplamente interdito ao desejo amoroso de Carlos: estado civil e mulher de parente próximo, condição agravada pela posição de hóspede do Santa Rosa. São termos que ocupam o mesmo lugar numa estrutura ética, manifestando o tema da "moça fina da cidade". No entanto, o apetite, apático com relação a Laura, despertado por Maria Chica, a erige, aos olhos de Carlos, em objeto investido, acima de tudo, do valor de fêmea. A valorização dela se processa como uma sedução fisica involuntária. $\mathrm{O}$ peso dessa forma de ser de Maria Alice para Carlos torna-se evidente pela justaposição, aos dotes conferidos pela natureza, do prestígio por ela conquistado junto ao rapaz e junto aos demais elementos da comunidade, numa estruturação harmônica:

"E o prestigio dela crescendo para as negras (menina dada! Era assim que as negras tratavam a sua franqueza, o seu jeito delicado de pedir as coisas). Crescendo para mim a mulher bonita, com aqueles olhos que se fechavam quando ria. com aquele seu macio encanto de flor" (p.54).

A passagem gradual de tcrmo proibido a termo prescrito numa relação amorosa se faz pela mediação do não-proibido. E este se realiza na figura de sonho - "E que sonho despudorado" - que voltará com as mesmas características na terceira parte do livro. É ainda essa localização de termo não-proibido que parece explicar a comutação de Maria Chica por Maria Alice no sonho. Observa-se que o parágrafo seguinte ao do sonho, inicia-se com a referência à relação carnal de Carlos e Maria Chica, porque esta representa na consciência do rapaz, o não proibido. $\mathrm{E}$ através desse percurso - proibido/não proibido/proscrito - que o processo amoroso se desenvolve em Carlos até atingir o ponto terminativo 


\section{a figura da mulher no imaginário masculino no mundo dos coronéis}

com que se abre o capitulo seguinte: "Quando abri os olhos estava apaixonado por Maria Alice" (p. 57).

A modalização de Carlos como sujeito de não-poder/não-querer, que o situa como agente passivo de una relação, expressa-se bem nos aspectos pontual de "quando abri os olhos" e perfectivo de "estava apaixonado". Essa modalização antecipa, coerentemente, a posição que lhe caberá na relação com Maria Alice. Da mesma forma, dentro de uma coesão figurativa, ganha sentido o fato de que a conscientização de si próprio se expresse através do olhar, do olho. A relação causa-efeito entre olhar/ser-tomado-de confirma-se logo em seguida pelo avesso ("aquela inquietude toda que me invadia. se por acaso deixasse de vêla...", p. 57) e pelo direito ("agitando-me não sei por que quando a via", p. 57). A qualificação de Maria Alice se faz ao modo do ser: ela é atraente, há nela a força da sedução. Ou seja, o ator aparece já investido de valores modais que a função de destinador, no programa de competência, lhe exige.

A estas alturas, pode-se concluir que Maria Alice, enquanto simulacro criado por Carlos, reúne as duas qualificações ausentes tanto em Laura quanto $\mathrm{cm}$ Maria Chica: na primeira, a carência da atração carnal e, na segunda, a da paixão. Isto equivale dizer que Maria Alice sana essa dupla carência do sujeito, que passa a modalizar-se como aquele que quer $\mathrm{e}$ pode querer.

A linguagem dos olhos passa, então, a efetuar-se não só como meio de percepção do outro, mas também como de comunicação ("ficava com medo que descobrisse a fome de meus olhos") que abre o canal de todos as demais ("o interesse material que todos os meus sentidos não podiam me conter", p. 60).

No desempenho da função de destinador, Maria Alice é aquela que capacita o sujeito a ollar e a ver. Daí que o torpor dos sentidos, resultante do insulamento após a sua chegada ao engenho, é quebrada não só pela competência de ver o outro como ainda de ver esse outro enriquecido pelo aspecto cromático. Em cadeia, também o olfato é 


\section{Tieko Yamaguchi Miyazaki}

despertado,criando um contraste significativo entre a primeira e segunda parte do romance.

Com relação ao cromático, a sua ausência na primeira parte é substituída na segunda pela recorrência do verde (do umbuzeiro, do flamboyant antes da florada e da caatinga no alto), do vermelho polarizado na semente do mulungu, nas flores do flamboyant, nos frutos de cardeiros $\mathrm{e}$ nas flores de orquidea. Já o olfato aparece não só em referências ao açafrão, ao carvão-de-pedra, ao cajá maduro, ao cajueiro, à baunilha e principalmente ao jasmim. E entre o cromático e o olfativo se estabelece uma relação de complementaridade, homologada pela configuração de uma dimensão espacial ampla, através do próprio modo de percepção desses dois componentes: em perspectiva (o flamboyant visto de longe) $\mathrm{cm}$ expansão (o cheiro intenso recendendo longe) ou a indicação de uma totalidade como em "E a mata cheirava". É com esse sentido, de abertura de canais de comunicação, que tanto o olhar quanto o cheirar entram na composição temático-figurativo do percurso amororoso desenvolvido por Carlos e Maria Alice. Mais particularmente, o olfato cria uma relação paradigmática entre a circunstância espacial do engenho e a visitante, que chega ao neto do coronel como cheiro: "Junto do seu corpo sempre a cheirar", diz Carlos, "me esquecia de todas as outras fraquezas" (p.73). E por ele se prolonga pelo tempo e pelo espaço. Daí comutação Maria Alice/jasmineiro, que se apreende bem pela sua recorrência ao longo da narrativa.

A primeira se dá logo após a investida inicial de Carlos junto a Maria Alice, o qual assim descreve a volta do passeio:

"Só ouviamos o rumor do engenho moendo. $A$ vida dos outros bem junto da gente. O pé de jasmim do portão cheirava, ao meio-dia em ponto. Sentado no alpendre, o velho Zé Paulino batendo com o cacete na calçada. Olhou-nos" (p. 70).

No texto, bastante conotativo, o estado eufórico do sujeito se explica pela aspectualização inceptiva de um programa que se visualiza em 


\section{a figura da mulher no imaginário masaulino no mundo dos coronéis}

sua virtualidade; a conquista de Maria Alice apresenta-se como possivel e Carlos se vê como sujeito de querer e poder querer (a mulher). Tal disposição parece ser sancionada positivamente, de um lado, pelo jasmineiro que, delegado de um destinador não identificado - o desejo do sujeito - cumpre zelosamente o seu papel no momento e no lugar certo, e, de outro, pelo avô, em quem, como se viu, também o olhar é a figura que se manifestam funções actanciais importantes. A segunda ocorrência se verifica quando, de volta de suas andanças enlouquecidas, Carlos observa a porta do quarto onde a moça dorme com o marido, às vésperas de sua partida:

"E uma réstia de lua estava bem em cima do Anjo Gabriel.

O diabo do jasmineiro cheirava como uma prostitula" (p.90).

E a terceira referência à planta fecha a segunda parte do romance. Após a partida da moça, diz o narrador:

"O anjo Gabriel de espada na mão, o outro com carneiro nos braços. São Severino num caixão de defunto, e o senhor morto de sangue correndo das feridas. Por que não rezava? Sentia o cheiro do jasmineiro" (p.94).

Comparando-se as três referências: a primeira no início da relação amorosa, a segunda na iminência da volta da visitante e a última, após a sua partida - a mudança tímica da qualificação da planta, ocorrida entre as duas primeiras referências, retrata a evolução do percurso narrativo; já a ausência de tal qualificação na última indicia a passagem da planta de substituta paradigmática a símbolo, fato que se confirma na terceira parte do romance quando, aquilatando a possibilidade de fazer da filha de Pinheiro sua companheira - "Teria eu uma vida feliz, de noites esquentadas com corpo de mulher, como aquelas noites de Maria Alice" (p. 150). Carlos traz a planta da porta da casa-grande para dentro dela: "Com o jasmineiro dentro de casa cheirando" (p. 150).

Entretanto é preciso notar o desencontro entre o ser e o parecer do 


\section{Tieko Yamaguchi Miyazaki}

desejado. Explicitamente, Carlos pretende substituir Maria Alice pela filha de Pinhero, declarando, desta forma, a disforia da relação carnal com Laura e a euforia dessa mesma relação no engenho. Por outro lado, o viés denunciado pela lembrança de Maria Alice indicia o desejo de Carlos de que seja também a substituta desta, fato poeticamente expresso pelo deslocamento espacial do jasmineiro de fora para dentro de casa $\mathrm{e}$ exalando perfume. $\mathbf{O}$ modo deceptivo, porém, de tal substituição logo é denunciado e exatamente através da figura da planta: "Secara o pé de jasmim. Não havia ali ninguém precisando dele".

Da mesma maneira, no campo cromático, este se polariza no vermelho, das flores de flamboyant sempre ao longe e o vermelho das sementes de mulungu. Com a partida de Maria Alice, a busca da visão delas indica a força de sua fragilidade como substituto metonimica.

"Ainda estavam vermelhos os mulungus. Também só via isto. aquele encarnado dando na vista com o sol em cima. Andara com Maria Alice por ali" (p. 85).

"Andei mais. De um alto avistei o flamboyant em chamas. tremendo ao vento. Maria Alice gostava de me mostrar esta árvore com deshumbramento " (p.62).

Corroborando essa relação, na mesma passagem há pouco citada da filha de Pinhero, a insinuação de Maria Alice se faz por esse processo de substituição:

"A filha do Pinheiro ia longe. hulindo com os quartos. E o pé de mulungu da estrada, pintado de vermelho, resplandecia com o sol da tarde" (p. 150).

Desta forma, pode-se dizer que jasmim enquanto olfato e mulunguflamboyant enquanto cor, equivalem-se. No entanto, com relação ao par cromático, a equivalência não se completa, na medida em que passam a configurar relações tensas pela diversidade dos contextos em que se realizam, conotando que, a partir do núcleo comum assinalado indicam o 


\section{a figura da mulher no imaginário masculino no mundo dos coronéis}

conflito do sujeito manifestando-se subliminarmente. A crença popular, segundo informa o próprio Carlos, atribui ao chá de semente de mulungu o poder de enlouquecer. Essa informação denuncia o modo deceptivo da presença desse vegetal em certos contextos como o acima transcrito: a localização do desejo de Carlos como não-verdadeiro, envolvendo a fillha de Pinheiro, se capta graças a esse dado sobre o mulungu. Por outro lado, o outro elemento que realiza o termo eufórico da categoria é oflamboyant que acena, ao longe, à interpretação errônea que Carlos faz das funções de Maria Alice. A justaposição de entrechos como o abaixo em que se narram as andanças de Carlos, perturbado com a notícia da partida de Maria Alice:

"O cavalo pisava em cima de sementes vermelhas de mulungn. O povo dizia que um chá daquilo fazia endoidar. Aonde ia assim? Botei-me para a caatinga para ver o roçado. no Riacho. Caroço de mulungu endoidava" (p. 86).

e este em que Carlos supõe ter Maria Alice

"olhado da janela do vagão o bueiro do Santa Rosa e o gameleiro alto (...). Eo flamboyant teria se mostrado mais mubro ainda, na despedida" (p. 93)

deixa clara a imagem do sujeito como o espaço de dois programas narrativos virtuais que o disputam: de um lado, o convite deceptivo de ceder à interpretação disfórica, resultante do despeito, do papel de Maria Alice; de outro, o convite veridico a compreender o papel de doador de competência da visitante: "Da porta da sala de jantar via o flamboyant dançando ao vento como uma bandeira de guerra" (p. 144).

Em síntese e em conclusão, o percurso narrativo do amor de Carlos e Maria Alice finaliza, de um lado, com a disjunção do sujeito de seu objeto amoroso mas, por outro, com a sua conjunção em um outro tipo de objeto: a reintegração na vida, através da reintegração dos sentidos, levando-o ao desejo de procriação. Nesse ponto, compreende-se por que, 


\section{Tieko Yamaguchi Miyazaki}

dentro do quadro traçado no início destas considerações sobre as mulheres do romance, Maria Alice, alienígena, não pode ser a parceira de procriação, papel reservado a Maria Chica. Não cabe a ela a função actancial de sujeito, juntamente com Carlos, do fazer que caracteriza o percurso do desempenho. $\mathrm{O}$ seu papel se restringe ao da competência: ela é a doadora dos valores modais necessários à performance do destinatário enquanto sujeito de querer (erguer o engenho).

Restam os demais valores modais para que se perfaça a aquisição da competência necessária ao fazer vitorioso.

\section{Bibliografia}

ARZUA FERREIRA, Edda. (1975). Integração e perspectiva.Rio de Janeiro, Cátedra.

BOSI, Alfredo. (1970). Introdução à fogo morto. In: Fogo Morto. 10 ed., Rio de Janeiro, José Olympio.

CÂNDIDO DE MELO E SOUSA, Antônio. (1945). Um romancista em decadência. Brigada Ligeira, São Paulo, Livraria Martins Editora.

CARPEAUX, Otto Maria. (1943). O brasileirissimo José Lins do Rego, In: Fogo Morto. Rio de Janeiro, José Olympio. (Reproduzio em Reflexos e realidade, Rio de Janeiro, Fontana, 1977. Public. póstuma).

CINTRA, Ismael Ângelo. (1972). Evolução narrativa em Banguê, Sitplemento Literário do Minas Gerais, Belo Horizonte, 12 fev.

CUNHA, Fausto. (1957). Perspectiva histórica de Fogo Morto. Correio da Manhã, Rio de Janeiro, 22 jun.

. (1968). As Jornadas Correio da Manhã, Rio de Janeiro, 3 nov. . (1973). Fogo Morto 30 anos depois. Jornal do Brasil, Rio de Janeiro, 6 out.

GRIECO, Agripino. (1935). Doidinho e Banguê. In: Gente Nova do Brasil. Rio de Janeiro, José Olympio.

IVO, Ledo. (1951). Em seu aniversário. Bota de Sete Léguas, Rio de Janeiro, A Noite.

LIMA, Luis Costa. (1968). III Regionalismo. O modernismo na ficção. 
a figura da mulher no imaginário masculino no mundo dos coronéis

In: A Literatura no Brasil (Dir. A. Coutinho). Rio de Janeiro, SulAmericana S.A., vol. v.

MONTEIRO, Adolfo Casais. (1938). Pureza. Boletim de Ariel, Rio de Janeiro, VII, n. 6, mar.

MONTELLO, Josué (1976). O romancista José Lins do Rego. Fiç̧ão completa de José Lins do Rego. Rio de Janeiro, Nova Aguillar.

PASSOS, Claribalte. (1972). O ciclo da cana-de-açucar na obra literária de José Lins do Rego. Brasil Açucareiro, Rio de Janeiro, ano XL, v. LXXX, jul.

SOBREIRA, Ivan Bichara. (1971). O romance de José Lins do Rego. João Pessoa, A União Editora. 